\title{
Non traditional cooling technique using Peltier effect for single point boron carbide (B4C) cutting tool doping with titanium carbide (TiC)
}

Reddy SREENIVASULU, Krishna Teja VALETI

DOI: 10.30464/jmee.2021.5.1.31

Cite this article as:

Sreenivasulu R., Valeti K. T. Non traditional cooling technique using Peltier effect for single point boron carbide (B4C) cutting tool doping with titanium carbide (TiC). Journal of Mechanical and Energy Engineering, Vol. 5(45), No. 1, 2021, pp. 31-38.

\section{VOLUME 5(45) | No. 1 | MARCH 2021}

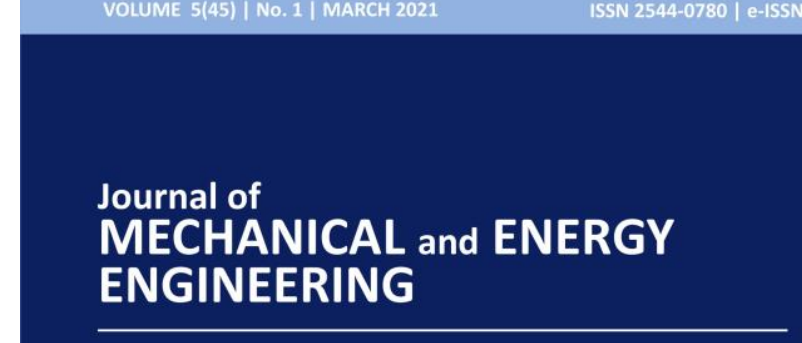

\section{Editor-in-Chief}

Waldemar Kuczyński

Editors

Krzysztof Nadolny
Journal of Mechanical and Energy

Engineering

Website: jmee.tu.koszalin.pl

ISSN (Print): 2544-0780

ISSN (Online): 2544-1671

Volume: 5(45)

Number: 1

Year: 2021

Pages: 31-38

Article Info:

Received 5 March 2021

Accepted 22 March 2021

\section{Open Access}

This article is distributed under the terms of the Creative Commons Attribution 4.0 (CC BY 4.0) International License (http://creativecommons.org/licenses/by/4.0/), which permits unrestricted use, distribution, and reproduction in any medium, provided you give appropriate credit to the original author(s) and the source, provide a link to the Creative Commons license, and indicate if changes were made. 


\title{
NON TRADITIONAL COOLING TECHNIQUE USING PELTIER EFFECT FOR SINGLE POINT BORON CARBIDE (B4C) CUTTING TOOL DOPING WITH TITANIUM CARBIDE (TIC)
}

\author{
Reddy SREENIVASULU ${ }^{1 *}$, Krishna Teja VALETI ${ }^{2}$ \\ ${ }^{1 *}$ R.V.R\&J.C.College of Engineering (Autonomous), Assistant Professor in the Department of Mechanical \\ Engineering, Guntur, Andhra Pradesh, INDIA - 522019. *e-mail: rslu1431@gmail.com \\ ${ }^{2}$ R.V.R\&J.C.College of Engineering (Autonomous), Final year B.Tech Student, Department of Mechanical \\ Engineering Guntur, Andhra Pradesh, INDIA - 522019
}

(Received 5 March 2021, Accepted 22 March 2021)

\begin{abstract}
A single point cutting tool is modeled out of two different materials having desired thermoelectric properties. The tool material used is Boron Carbide (B4C) doped with different compositions of Titanium Carbide (TiC). In the present work, three different compositions of Titanium Carbide doped on both sides of cutting tool made by Boron carbide. The available combinations of Titanium Carbide (TiC) from the work bench in ANSYS was selected with three cases of $0 \& 25.4 \%, 0 \% \& 12.5 \%$ and $12.5 \% \& 25.4 \%$ on first half and second half of the cutting tool respectively. The simulation process is done in ANSYS $2020 \mathrm{R} 2$ software, thermal-electric module (TEM) is used. From these studies it is evident that considerable cooling effect is achieved and found to be the lowest temperature of $10.93^{\circ} \mathrm{C}$ is observed for the combination of $0 \% \& 25.4 \%, 18.79^{\circ} \mathrm{C}$ is observed for the combination of $0 \& 12.5 \%$ and $26.73^{\circ} \mathrm{C}$ for $12.5 \%$ and $25.4 \%$ combination at the junction of the tool material which is nearer to the cutting tip respectively. Finally it is concluded that one side of cutting tool without any doping and other side with $25.4 \% \mathrm{TiC}$ doped showed good results which observed by conducting number of simulations at different levels of iterations for Titanium Carbide doped Boron Carbide cutting tool used in turning operation.
\end{abstract}

Keywords: peltier cooling effect, thermoelectric module, ANSYS 2020 R2, titanium carbide, solidworks 2020, boron carbide cutting tool

\section{INTRODUCTION}

In the machining process by cutting, a part of mechanical energy used to remove material from the workpiece is transformed into thermal energy developing heat sources which causes heating of the cutting tool as well as workpiece. The major quantity of thus generated heat goes away with chips, while a minor part is retained within the workpiece and the cutting tool. From the practical aspect, the heat transferred to the tool and workpiece is of special importance. This primarily reflects the machinability of a workpiece, that is, the accuracy of shapes and dimensions, quality of the machined surface and tool wear. The heat sources on the tool are located on the cutting wedge. Knowledge of the temperature fields in chips, workpiece and, before all, the tool makes it possible to adjust better the cooling conditions and therefore to reduce unfavourable influences of thermic actions. Lowering of the temperature in the cutting tool is of special importance for reduction of wear and improvement of accuracy of machining. The phenomenon of heat generation as well as the methods of reducing it have been studied in detail, in an effort to prolong the periods between regrinds and get more metal removal in a shorter period of time. One of the simplest and most widely used method used is to play a jet of cutting fluid at the point on the tool where the cutting is taking place. However, the fluid would be carried away by the outward flowing chip more rapidly than it was drawn between the interstices between the chip and tool by capillary forces. In order to increase the effectiveness, additives are added to the 
coolants which have negative effects on job, they are even more costly and toxic to humans. The other technique used was to blow carbon dioxide gas on to the tool chip interference, which is also dangerous. In case of increased requirements for the quality of the machined surface high-speed machining is more increasingly used where it is not possible to apply classical means for cooling and lubrication. In such cases dry machining with no cutting fliud is more economical but due to friction between tool and workpiece surface quality decreases. Such conditions of machining increase heating of the cutting tools which leads to its more intensive wear as well.Thermoelectric modules (TEM) in the cooling system in industry find very broad and diversified use. In order to solve the problem of cooling in dry machining the idea has developed to try with application of thermoelectric cooling of cutting tools. The central topic of this paper is theoretical investigation of the possibility of applying thermoelectric cooling of cutting tools. Using the known mathematical, analytical and numerical models in the temperature fields in the tools as a base of simulation model with the assistance of FEM takes into consideration to cool the tool itself by thermoelectric module.

In the present study, modeling and simulation is performed using solid works and ANSYS 2020 R2 software's and obtained temperatures for three different compositions to the tungsten carbide cutting tool doped with B4C and observed satisfied results (algorithm of present study illustrated using flow chart shown in Fig.1).

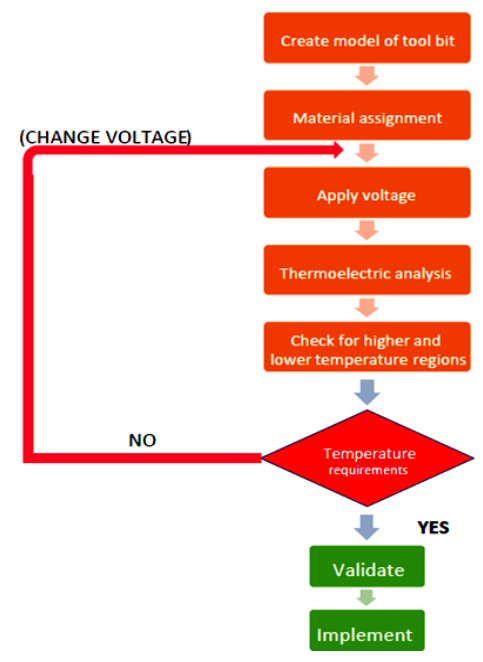

Fig. 1. Flow chart for proposed method

\section{BACKGROUND LITERATURE}

Research investigators have attempted to measure these cutting temperatures with various techniques. The main techniques used to evaluate the temperature during machining (tool chip thermocouple, embedded thermocouple, and thermal radiation method) have been reviewed by Barrow [1]. Machining without the use of any cutting fluid (dry or green machining) is becoming increasingly more popular due to concern regarding the safety of the environment [2]. Interfacial temperatures in machining play a major role in tool wear and can also result in modifications to the properties of the workpiece and tool materials. As there is a general move towards dry machining, for environmental reasons, it is increasingly important to understand how machining temperatures are affected by the process variables involved. Sullivon et al. [3] conducted initial experiments which involves the simultaneous measurement of forces and temperature. These experiments focused on the use of embedded thermocouples (in the workpiece) and using the infrared thermal camera to monitor the process. Accurate and repeatable heat and temperature prediction remains challenging due to the complexity of the contact phenomena in the cutting process. latest work on estimation of heat generation, heat partition and temperature distribution in metal machining is reviewed by N.A.Abukhshim et al. [4]. Patwari et al. [5] provided a concept of using peltier cooling effects during aluminium milling operation has been presented and adopted with an aim to improve surface roughness of the machined surface. Previously numerous authors used different techniques in measurement of temperature exerted during machining and found thermoelectric methods best suitable techniques conventionally [6]. The effect of the cutting temperature is mostly detrimental to both the tool and the job. The major portion of the heat is taken away by the chips. In shear zone, maximum heat is produced because of the plastic deformation of metal, and all of this heat is carried away by the chip. A very small amount of this heat $(5-10 \%)$ is conducted to work piece. In friction zone, the heat is produced due to friction between moving chip and tool face and slightly due to secondary deformation of the built up edge. In work-tool contact zone, the heat is produced due to friction between tool and workpiece. It should be noted that the maximum temperature occurs slightly away from the cutting edge and not at the cutting edge [10]. McLachlan et al. [7] stated that by selecting an optimum combination of different materials improve the thermoelectric properties. Chakraborty et al. [8] provide detailed information towards the future of carbon-based thermoelectric in their critical review and also discussed on basic design of various thermo electric materials. Darukhanavala [9] discussed in detail about thermo electric cooling methods especially in lathe cutting tool in his text book. 


\section{SOLID MODELING OF A CUTTING TOOL}

Procedure for modelling of cutting tool in Solidworks

1. Open Solidworks software and select New Part.

2. Select the Sketch Tool bar, Select Right Plane and click on sketch.

3. Select Corner-Rectangle from the sketch tool bar. Draw a rectangle placing one corner at the origin.Select Smart Dimensions and give the dimensions of $25 \mathrm{~mm} * 25 \mathrm{~mm}$ to the rectangle. Click exit sketch.

4. Click on Extruded Boss option from the Features tool bar, select the rectangle sketch and give the length as $130 \mathrm{~mm}$. Click OK.

5. The entire tool profiling is done by following the given procedure: Select the right side face of the body, right click, select sketch option and draw an inclined line joining the top and bottom lines of the face. Similarly draw another line on the top face of the body which meets the previous line. Select sketch on front face, draw a line from top right corner to the left vertical line, and constrain the line by defining the angle between it and upper horizontal line as $20^{\circ}$ [Side Rake Angle]. Similarly draw an inclined line on the right face from the top left corner and constrain it by defining the angle between it and upper horizontal line as $10^{\circ}$ [Back Rake Angle]. Draw a triangular profile on the same face, which includes back rake angle, the two corresponding sides. Draw a rectangle on the left side face, whose corner and the corresponding sides coincides with that of the top right corner of the body. And the adjacent corner coincides with the inclined line on the top face. Click on Lofted Cut from the features tool bar, select the above triangular and rectangle sketches under profile selection and select the side rake angle line under the path selection. Click OK. Now, construct a plane along the inclined line on the right side face. Select Draft from features tool bar, select the above plane under Neutral Plane, right side face under Faces to Draft and give Draft Angle as $8^{\circ}$ [Side Cutting Edge Angle]. Click OK. Construct another plane which is parallel to the Top plane and passes through the cutting tip of the tool. Now select Draft, select the above plane as Neutral plane, Front face as the Faces to Draft and draft angle as $7^{\circ}$ [End Clearance Angle]. Similarly construct a plane, parallel to the Right plane and passing through the cutting tool tip. In Draft select the above plane, front face and give Draft angle as $7^{\circ}$ [End Cutting Angle]. Select Fillet from the features tool bar, select the nose line under the cutting tool tip and give fillet radius as $0.8 \mathrm{~mm}$ [Nose Radius]. Now, we have a Single Point Cutting Tool, with standard tool signature.
6. Select the top face of the tool flank for sketching; draw an elongated hole with centre distance $90 \mathrm{~mm}$ and radius of $2.5 \mathrm{~mm}$. Finish the sketch. Click on Extrude Cut from the features tool bar, select the above sketch and make a slot through the tool body.

7. Draw a rectangle on one leg of the above formed tool body at the centre with $2 \mathrm{~mm}$ width and make a slot through the leg as in STEP 6.

8. Draw a straight line along the centre of the tool body, on the top face and draw a perpendicular line to it at the tool boy and tip interface.Search for Split command in the search bar, select the above perpendicular lines under Trimming Tool selection and the tool body under Bodies to be Split. Click ok. Now we have a Single Point Cutting Tool, split into four bodies in order to accommodate different material properties and also for the voltage input.

A single point cutting tool was designed with tool signature of 0-7-6-8-15-16-0.8, in Solidworks2020 is shown in Fig.2. A slot was provided to the shank to accommodate voltage input and the whole shank was split into two sections as to provide different material properties. The reduced strength in the tool can be compensated by using non-metallic bushes in between the slot. The isometric and top views of the tool are shown below. After obtain the solid model of cutting tool with provision for embedding the thermo couples and doping of B4C using solid works software package then the model exported to ANSYS for further analysis.

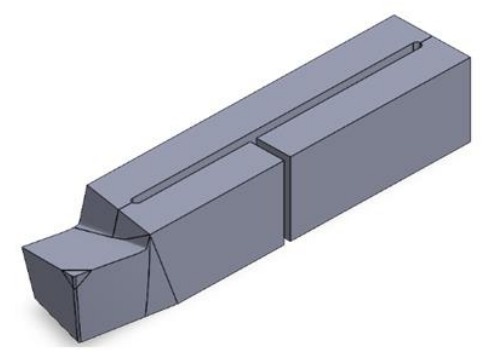

Fig. 2. Single point cutting tool model developed in solid works

\section{ANALYSIS OF A PELTIER COOLING ON CUTTING TOOL ANSYS 2020 R2}

The cutting tool is represented by a square cross section with rectangular block shape and is modeled as a rigid body. A fine mesh density is defined with an input size of $2 \mathrm{~mm}$. Thermal boundary conditions are defined keeping in view that it will allow heat transfer from work piece to cutting tool. Heat transfer between the work piece and the tool is dependent on the cutting force developed during turning operation. The cutting tool is modeled as a rigid body using 30000 (polygon) elements with 20000 nodes. Step by step procedure to 
simulate the study in ANSYS 2020 R2 and depicted the pictorial information in details (micro level) in following figures or diagrams represented with labels from Fig. 3 to Fig. 10 for case -I, Fig. 11 to Fig. 18 for case-II and Fig. 19 to Fig. 24 for case-III. The setup is solved for different combinations of materials and at different voltage inputs. The corresponding simulation results of three cases are as follows.

CASE-1: For $\mathrm{B}_{4} \mathrm{C}$ cutting tool with $0 \%$ \& $25.4 \% \mathrm{TiC}$ doping.

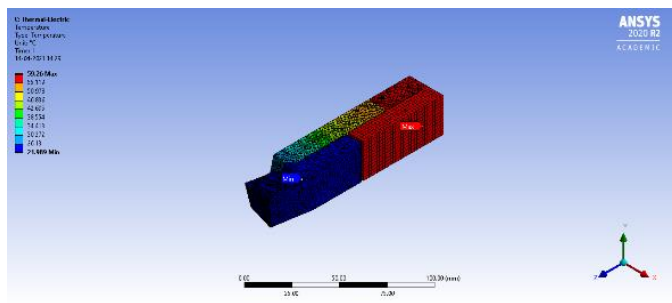

Fig. 3. Temperature at $3 \mathrm{~V}$

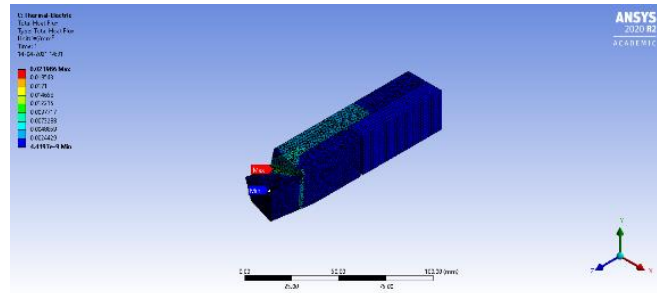

Fig. 4. Total heat flux at $3 \mathrm{~V}$

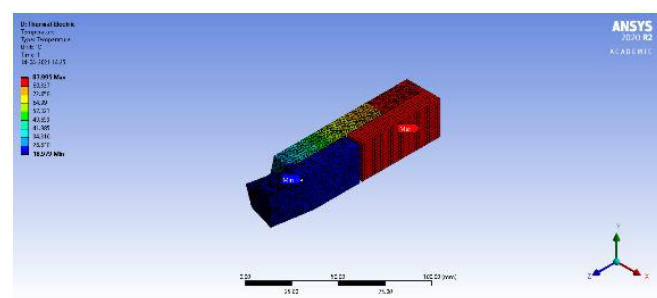

Fig. 5. Temperature at $4 \mathrm{~V}$

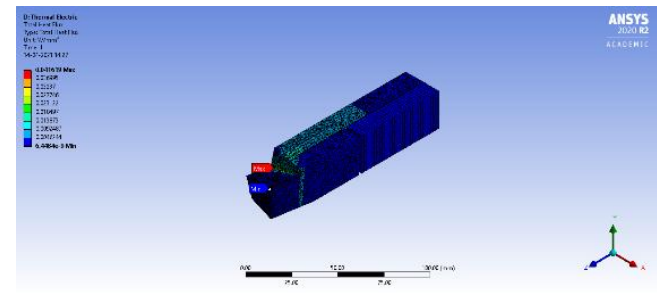

Fig. 6. Total heat flux at $4 \mathrm{~V}$

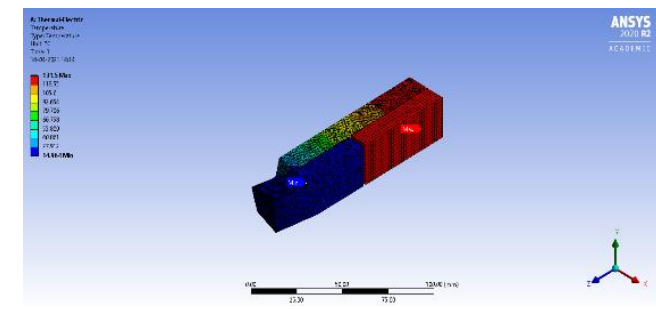

Fig. 7. Temperature at $5 \mathrm{~V}$

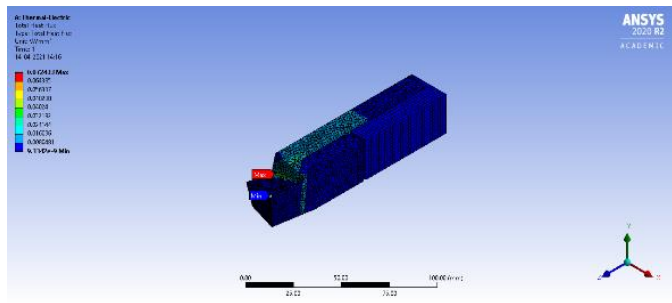

Fig. 8. Total heat flux at $5 \mathrm{~V}$

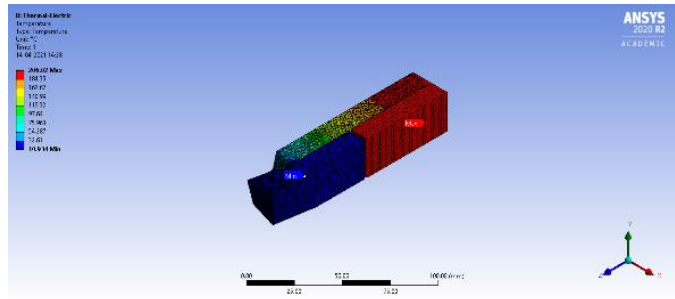

Fig. 9. Temperature at $6 \mathrm{~V}$

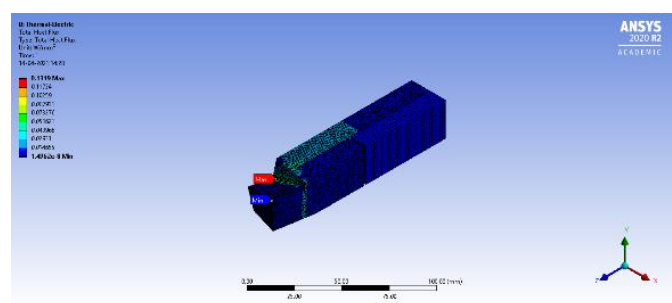

Fig. 10. Total heat flux at $6 \mathrm{~V}$

CASE-2: For $\mathrm{B}_{4} \mathrm{C}$ cutting tool with $0 \%$ $\& 12.5 \% \mathrm{TiC}$ doping.

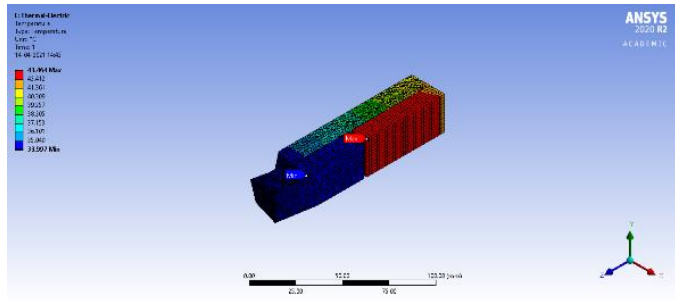

Fig. 11. Temperature at $15 \mathrm{~V}$ 


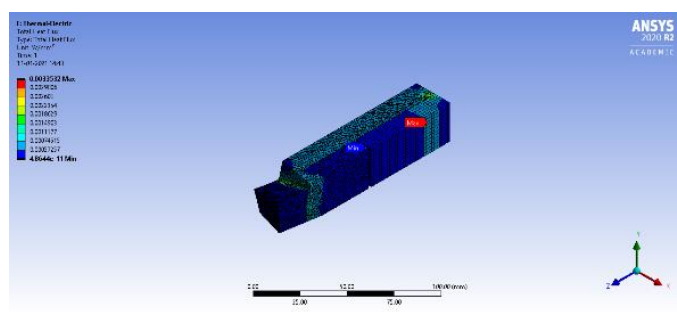

Fig. 12. Total heat flux at $15 \mathrm{~V}$

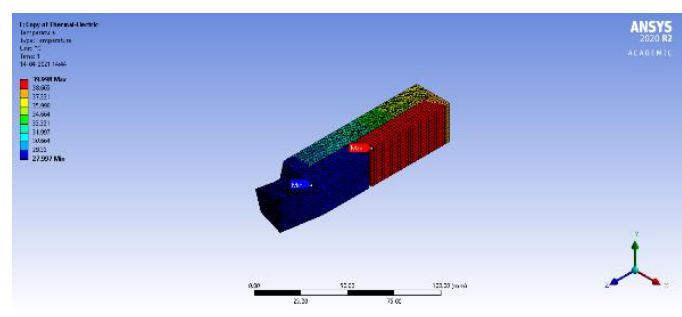

Fig. 13. Temperature at $17 \mathrm{~V}$

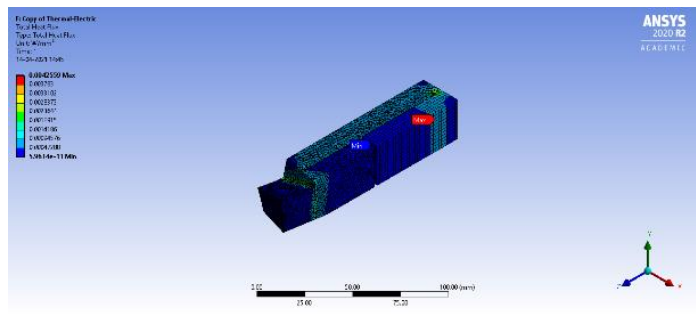

Fig. 14. Total heat flux at $17 \mathrm{~V}$

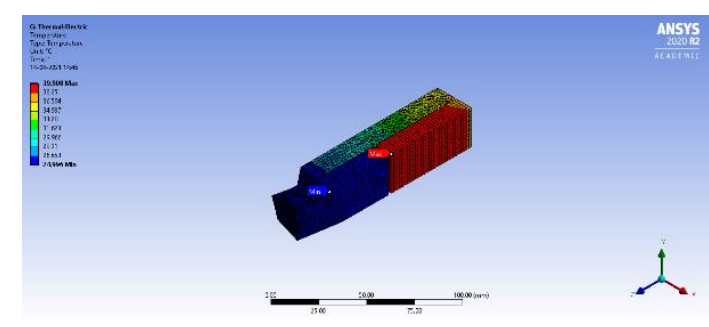

Fig. 15. Temperature at $19 \mathrm{~V}$

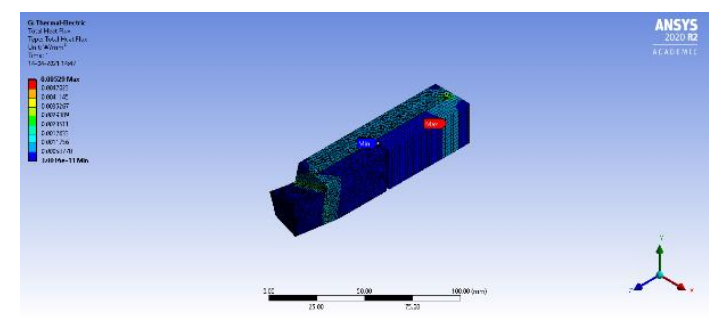

Fig. 16. Total heat flux at $19 \mathrm{~V}$

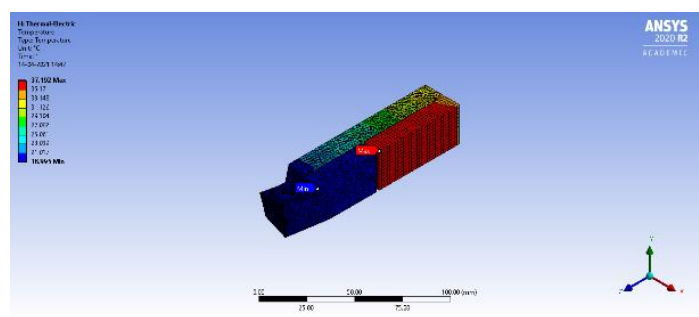

Fig. 17. Temperature at $21 \mathrm{~V}$

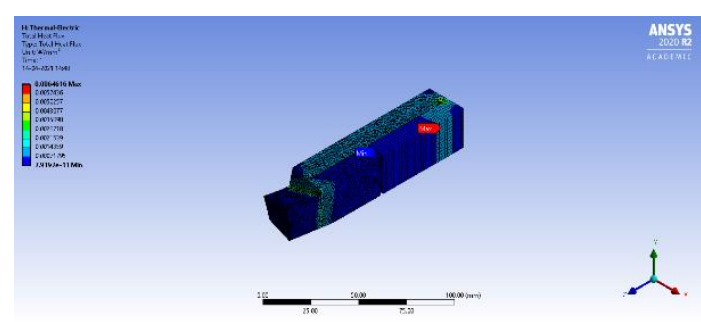

Fig. 18. Total heat flux at $21 \mathrm{~V}$

CASE-3: For $\mathrm{B}_{4} \mathrm{C}$ cutting tool with $12.5 \%$ \& $25.4 \% \mathrm{TiC}$ doping.

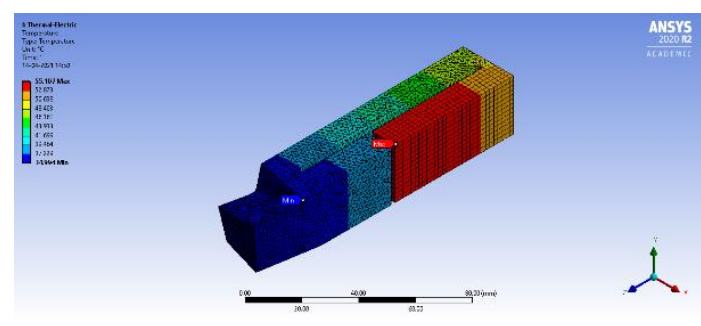

Fig. 19. Temperature at $27 \mathrm{~V}$

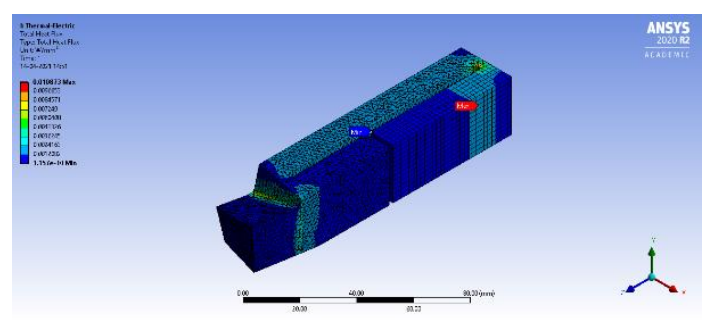

Fig. 20. Total heat flux at $27 \mathrm{~V}$

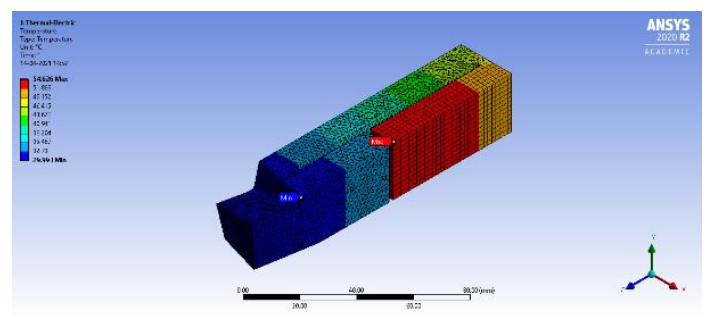

Fig. 21. Temperature at $30 \mathrm{~V}$ 


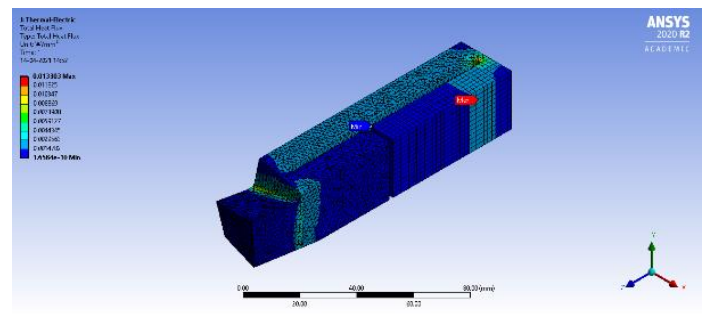

Fig. 22. Total heat flux at $30 \mathrm{~V}$

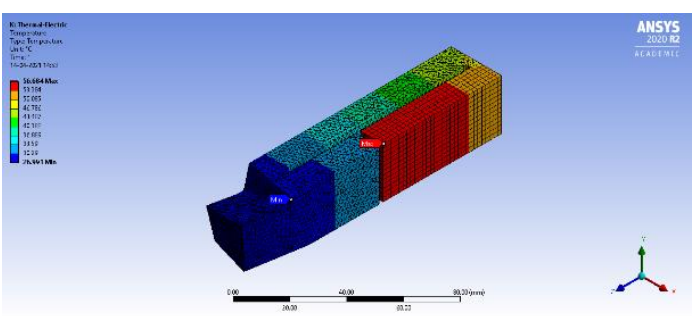

Fig. 23. Temperature at $33 \mathrm{~V}$

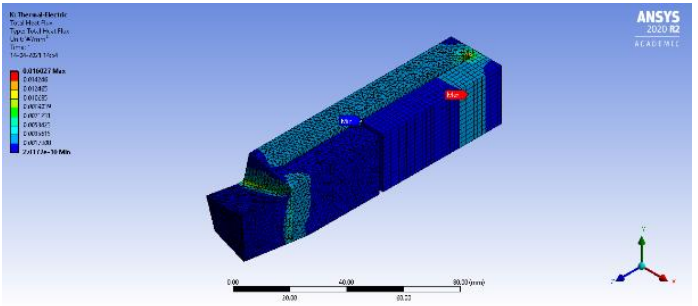

Fig. 24. Total heat flux at $33 \mathrm{~V}$

\section{RESULTS AND DISCUSSIONS}

The thermoelectric module (TEM) using Peltier cooling on single point cutting tool tip during turning operation studied by design, modeling using solid works 2020 software package and simulation using ANSYS 2020 R2 version by choosing p- doping with TiC with three levels of compositions studied under this project. The output values generated by feeding the predefined inputs in to the ANSYS and depicted these readings in the Table 1 , Table 2 and Table 3. Finally draw the graphs to identify the variation of temperature with voltage. Apart from temperature distribution intensity of heat flux along the cutting tool surface also plotted against the variation of input voltage.

Tab. 1. Recorded outputs of temperature and total heat flux w.r.t supplied voltage to a Peltier cooling circuit for different composition of $\mathrm{TiC}$ doped with $\mathrm{B} 4 \mathrm{C}$ cutting tool

\begin{tabular}{cccc}
\hline \multicolumn{4}{c}{ Results for $\mathrm{B}_{4} \mathrm{C}-0 \%$} \\
$\begin{array}{c}\text { Voltage, } \\
\mathrm{V}\end{array}$ & $\begin{array}{c}\text { Low } \\
\text { temperature, } \\
{ }^{\circ} \mathrm{C}\end{array}$ & $\begin{array}{c}\text { High } \\
\text { temperature, } \\
{ }^{\circ} \mathrm{C}\end{array}$ & $\begin{array}{c}\text { Total heat } \\
\text { flux, } \\
\mathrm{w} / \mathrm{mm}^{2}\end{array}$ \\
\hline 3 & 21.989 & 59.26 & 0.02198 \\
\hline 4 & 18.971 & 87.99 & 0.04169 \\
\hline 5 & 14.962 & 131.51 & 0.0724 \\
\hline 6 & 10.934 & 208.69 & 0.1319 \\
\hline
\end{tabular}

Tab. 2. Recorded outputs of temperature and total heat flux w.r.t supplied voltage to a Peltier cooling circuit for different composition of $\mathrm{TiC}$ doped with $\mathrm{B} 4 \mathrm{C}$ cutting tool

\begin{tabular}{|c|c|c|c|}
\hline \multicolumn{4}{|c|}{ Results for $\mathrm{B}_{4} \mathrm{C}-0 \% \mathrm{TiC} \& \mathrm{~B}_{4} \mathrm{C}-12.5 \% \mathrm{TiC}$} \\
\hline $\begin{array}{c}\text { Voltage, } \\
\text { V }\end{array}$ & $\begin{array}{c}\text { Low } \\
\text { temperature, } \\
{ }^{\circ} \mathrm{C}\end{array}$ & $\begin{array}{c}\text { High } \\
\text { temperature, } \\
{ }^{\circ} \mathrm{C}\end{array}$ & $\begin{array}{l}\text { Total heat } \\
\text { flux, } \\
\text { w/mm }{ }^{2}\end{array}$ \\
\hline 15 & 33.89 & 54.464 & 0.00335 \\
\hline 17 & 27.52 & 99.981 & 0.00425 \\
\hline 19 & 24.69 & 197.331 & 0.00529 \\
\hline 21 & 18.79 & 207.192 & 0.00646 \\
\hline
\end{tabular}

Tab. 3. Recorded outputs of temperature and total heat flux w.r.t supplied voltage to a Peltier cooling circuit for different composition of $\mathrm{TiC}$ doped with B4C cutting tool

\begin{tabular}{cccc}
\hline \multicolumn{4}{c}{ Results for $\mathrm{B}_{4} \mathrm{C}-12.5 \%$} \\
\hline $\begin{array}{c}\text { Voltage, } \\
\mathrm{V}\end{array}$ & $\begin{array}{c}\text { Low } \\
\text { temperature, } \\
{ }^{\circ} \mathrm{C}\end{array}$ & $\begin{array}{c}\text { High } \\
\text { temperature, } \\
{ }^{\circ} \mathrm{C}\end{array}$ & $\begin{array}{c}\text { Total heat } \\
\text { flux, } \\
\text { w/mm }\end{array}$ \\
\hline 27 & 34.61 & 55.107 & 0.010873 \\
\hline 30 & 29.92 & 54.626 & 0.013303 \\
\hline 33 & 26.73 & 66.683 & 0.013027 \\
\hline
\end{tabular}

From the graphs (shown in Fig. 25 to Fig. 27), it is evident that considerable cooling effect is achieved and found to be the lowest temperature of $10.93^{\circ} \mathrm{C}$ is observed for doping combination of $0 \% \& 25.4 \% \mathrm{TiC}$, $18.79^{\circ} \mathrm{C}$ is observed for $0 \% \& 12.5 \% \mathrm{TiC}$ and $26.73^{\circ} \mathrm{C}$ for $12.5 \% \& 25.4 \% \mathrm{TiC}$ at the junction of the cutting tool of $\mathrm{B} 4 \mathrm{C}$ and work piece which is nearer to the cutting tip respectively. The relation between voltages to temperature is found to be almost linear relationship for lower temperature that means cooling. From the graph shown in Fig. 28, it is revealed that the dissipation of heat produced from electricity per unit area along the cutting tool surface with respect to variation in the applied voltage under the Peltier cooling circuit found to be increasing slope by increasing the voltage for $0 \%$ to $25.4 \%$ TiC. From the graph shown in Fig. 29, it is observed that the dissipation of heat produced from electricity per unit area along the cutting tool surface with respect to variation in the applied voltage under the Peltier cooling circuit found to be increasing slope by increasing the voltage for $0 \%$ to $12.5 \%$ TiC but very small amount of heat flux may be found under this doping composition. From the graph shown in Fig. 30, it is evident that the dissipation of heat produced from electricity per unit area along the cutting tool surface with respect to variation in the applied voltage under the Peltier cooling circuit found to be raised sudden increasing slope beyond the $30 \mathrm{~V}$ input voltage for $12.5 \%$ to $25.4 \%$ TiC combination at the junction of the materials which is nearer to the cutting tip.

Finally it is concluded that one side of cutting tool made by B4C without any doping and other side with 
25.4\% TiC showed good results which observed by conducting number of simulations at different levels of iterations for B4C cutting tool doped with titanium carbide used in turning operation.

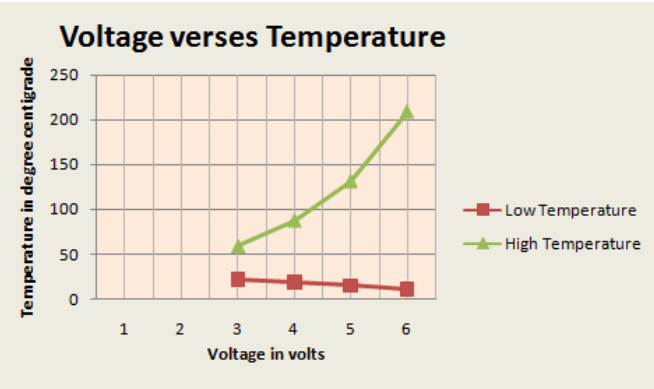

Fig. 25. Graph showing the relation between voltage verses temperature $\left(\mathrm{B}_{4} \mathrm{C}-0 \%\right.$ of $\mathrm{TiC} \& \mathrm{~B}_{4} \mathrm{C}-25.4 \%$ of $\left.\mathrm{TiC}\right)$

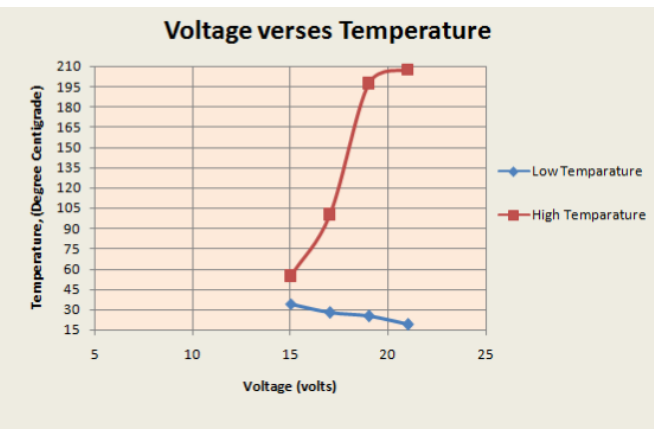

Fig. 26. Graph showing the relation between voltage verses temperature $\left(\mathrm{B}_{4} \mathrm{C}-0 \%\right.$ of $\mathrm{TiC} \& \mathrm{~B}_{4} \mathrm{C}-12.5 \%$ of $\left.\mathrm{TiC}\right)$

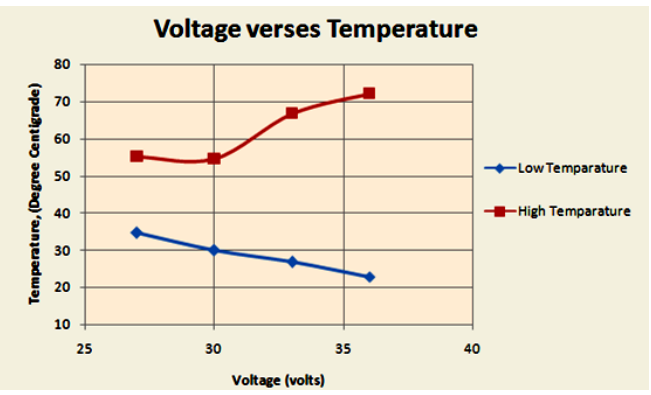

Fig. 27. Graph showing the relation between voltages verses temperature $\left(\mathrm{B}_{4} \mathrm{C}-12.5 \% \mathrm{TiC} \& \mathrm{~B}_{4} \mathrm{C}-25.4 \% \mathrm{TiC}\right)$

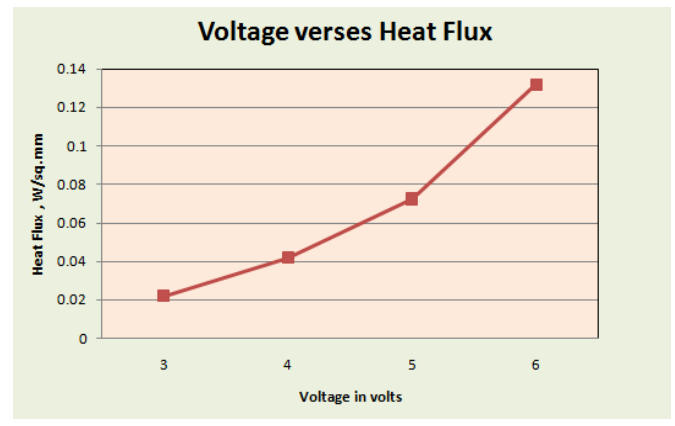

Fig. 28. Graph showing the relation between voltages verses heat flux $\left(\mathrm{B}_{4} \mathrm{C}-0 \% \mathrm{TiC} \& \mathrm{~B}_{4} \mathrm{C}-25.4 \% \mathrm{TiC}\right)$

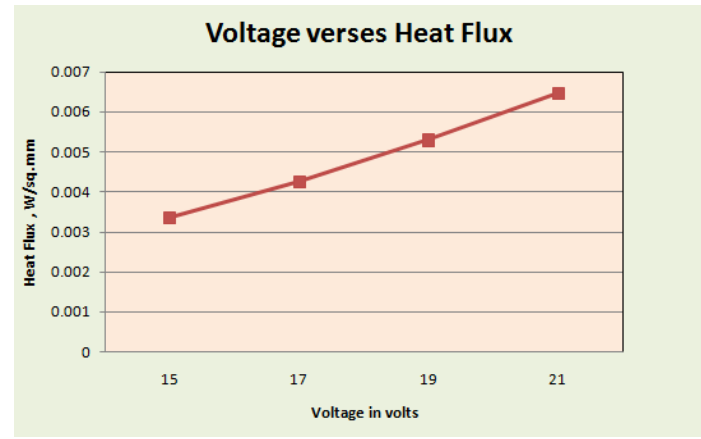

Fig. 29. Graph showing the relation between voltages verses heat flux $\left(\mathrm{B}_{4} \mathrm{C}-0 \%\right.$ \& $\left.\mathrm{B}_{4} \mathrm{C}-12.5 \%\right)$

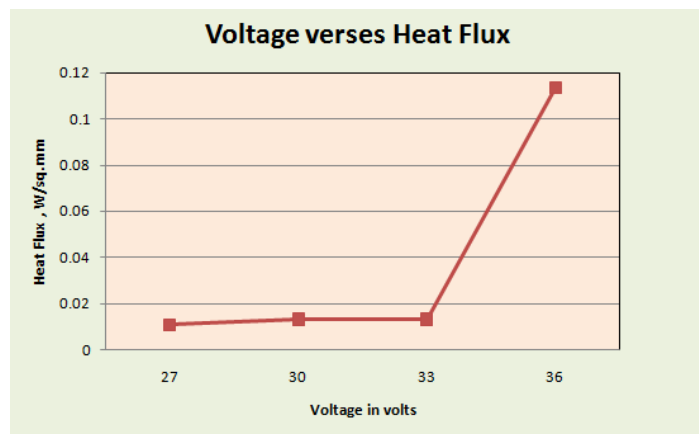

Fig. 30. Graph showing the relation between voltages verses heat flux $\left(\mathrm{B}_{4} \mathrm{C}-12.5 \%\right.$ \& $\left.\mathrm{B}_{4} \mathrm{C}-25.4 \%\right)$

\section{CONCLUSIONS}

In this simulation study using ANSYS conducted on dry machining (without any cutting fluids) of turning operation with single point cutting tool connected by thermo couples and cooling effect created to the tool by peltier effect principle and found the following conclusions.

1. Lowest temperature of $10.93^{\circ} \mathrm{C}$ is observed for $0 \& 25.4 \%$ combination of doping at the junction between the workpiece and the cutting tip respectively.

2. The dissipation of heat produced from electricity per unit area along the cutting tool surface with respect to variation in the applied voltage under the Peltier cooling found to be increasing slope by increasing the voltage for $0 \%$ \& $25.4 \%$ combination doping but very small amount of heat flux to be observed in the case of $0 \% \& 12.5 \%$ doping and it is raised suddenly beyond the $30 \mathrm{~V}$ voltage as input under $12.5 \% \quad \& 25.4 \%$ doping which identified from the simulation results.

\section{Acknowledgements}

We are sincerely thankful to the Principal, Head of the mechanical engineering department and computer lab incharge of R.V.R\&J.C.College of Engineering (Autonomous) to permit and utilize the CAD \& ANSYS lab facilities to complete this work. 


\section{Nomenclature}

$\mathrm{TiC}-$ Titanium Carbide

$\mathrm{B}_{4} \mathrm{C}-$ Boron Carbide

\section{References}

1. Murarka, P.D., Hinduja, S. and Barrow, G. (1981). Influence of strain, strain-rate and temperature on the flow stress in the primary deformation zone in metal cutting. International Journal of Machine Tool Design and Research, Vol 21 (3-4), pp. 207-216.

2. Sreejith, P.S. and Ngoi, B.K.A. (2000). Dry machining: machining of the future. Journal of materials processing technology, Vol 101 (1-3), pp. 287-291.

3. O'Sullivan, D. and Cotterell, M. (2001) Temperature measurement in single point turning. Journal of materials processing technology, Vol 118 (1-3), pp. 301308.

4. Abukhshim, N.A., Mativenga, P.T. and Sheikh, M.A. (2006). Heat generation and temperature prediction in metal cutting: A review and implications for high speed machining. International Journal of Machine Tools and Manufacture, Vol 46 (7-8), pp. 782-800.

5. Patwari, M.A.U, Habib, M.A., Ehsan, M.T., Ahnaf, M.G. \& Chowdhury M.S. (2017). An innovative green cooling approach using peltier chip in milling operation for surface roughness improvement. International Journal of Industrial and Manufacturing Engineering, Vol 11(7), pp. 1303-1307.

6. Byrne, G. (1987). Thermoelectric signal characteristics and average interfacial temperatures in the machining of metals under geometrically defined conditions, International Journal of Machine Tools and Manufacture, Vol 27 (2), pp. 215-224.

7. Nan, C.W, Paderno, Y. \& McLachlan D.S. (2000) Effect of titanium carbide addition on the thermo electric properties of boron carbide ceramics, Solid state communications, Vol 115, Issue10, pp. 523-526.

8. Chakraborty P., Ma, T., Zahiri A.H., Cao, L. \& Wang, Y. (2018) Carbon based materials for thermoelectrics Advances in Condensed Matter Physics, Article ID 3898479, 29 pages.

9. Darukhanavala, J.P. (1965) Thermoelectric cooling of a lathe cutting tool, Master's thesis, Department of industrial Engineering, Kansas State University, Manhattan, Kansas, pp 48-52.

10. Stephenson, D.A. and Agapiou, J.S.(2016). Metal cutting theory and practice, pp 29-31, CRC press.

11. Sreenivasulu, R., \& SrinivasaRao, C. (2018). Modelling, Simulation and Experimental validation of Burr size in Drilling of Aluminium 6061 alloy. Procedia Manufacturing, Vol 20, pp 458-463.

12. Sreenivasulu, Reddy, and C. Srinivasa Rao.(2013) Modeling and optimization of thrust force and torque during drilling of aluminum 6061 alloy using taguchigrey analysis approach. Int $J$ Adv Mat Manuf Characterization, Vol 3, pp 413-418.

\section{Biographical note}

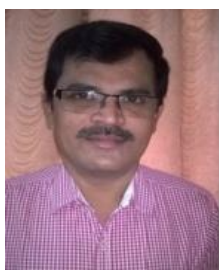

Reddy Sreenivasulu is an Assistant Professor in the department of Mechanical Engineering, R.V.R \& J.C College of Engineering (A) Guntur, Andhra Pradesh, India. He received Ph.D degree in Mechanical Engineering from Andhra University, Visakhapatnam in the year 2018, M.E degree from the Osmania University, Hyderabad in Automation \& Robotics in the year 2003 and B.Tech degree from the Regional Engineering College Warangal in Mechanical Engineering in the year 1997. He has 18 years of teaching experience. His area of research interest includes design of experiments, robotics, modeling and analysis of manufacturing processes and optimization. He has published more than 60 research papers in the international journal/conferences proceedings and acting as a reviewer for a peer reviewed referred journals. The remaining author Krishna Teja V. is pursuing final year B.Tech in Mechanical Engineering from R.V.R\&J.C. College of Engineering (Autonomous), Guntur, Andhra Pradesh. 